\title{
IMAGINACIÓN SOCIOLÓGICA PARA ESTUDIAR JUVENTUDES
}

\author{
MANuel CANALES CERÓN ${ }^{1}$ \\ KLAUDio DUARTE QUAPPER ${ }^{2}$
}

\begin{abstract}
RESUMEN
En la Sociología, se insiste en la relevancia que tiene el aporte de W. Mills con su propuesta de la imaginación sociológica como una forma de desplegar el conocimiento en la sociedad, así como la elaboración de alternativas de transformación en ella. En la presente conversación, el sociólogo chileno Manuel Canales Cerón reflexiona sobre las formas en que la observación densa de las dinámicas juveniles en diversos procesos históricos permiten el despliegue de este modo de comprensión de lo social. Para ello conecta su biografía como estudiante de sociología, como educador en experiencias poblacionales en tiempos de dictadura y su actual trabajo como cientista social. En la propia reflexión va conectando su biografía, contexto histórico y condiciones estructurales, las mismas tres dimensiones que, en su oficio, utiliza para el análisis crítico de lo juvenil, las mismas tres que sostienen la propuesta de la imaginación sociológica.
\end{abstract}

PALABRAS CLAVE: LO JUVENIL, IMAGINACIÓN SOCIOLÓGICA, BIOGRAFÍA, HISTORIA, ESTRUCTURA.

1 Doctor en Sociología, Universidad Complutense de Madrid. Académico de la Universidad de Chile. Correo electrónico: mcanalesc@gmail.com

${ }^{2}$ Sociólogo y Educador popular. Académico Universidad de Chile. Correo electrónico: claudioduarte@uchile.cl 


\title{
IMAGINAÇÃO SOCIOLÓGICA PARA ESTUDAR JUVENTUDES
}

\begin{abstract}
RESUMO
Na Sociologia, há uma ênfase particular na relevância da contribuição de W. Mills com sua proposta da imaginação sociológica como uma forma de exibir o conhecimento na sociedade, bem como a elaboração de alternativas de transformação nela. Na presente conversa, o sociólogo chileno Manuel Canales Cerón reflete sobre as formas em que a observação densa das dinâmicas juvenis em diversos processos históricos permite a exibição deste modo de compreensão do social. Para isso, conecta sua biografia como estudante de sociologia, como educador em experiências marginais em tempos de ditadura e seu trabalho atual como cientista social. Na própria reflexão conecta sua biografia, contexto histórico e condições estruturais, as mesmas três dimensões que, em seu ofício, utiliza para a análise crítica do juvenil, as mesmas três que sustentam a proposta da imaginação sociológica.

PALAVRAS-CHAVE: O JUVENIL, IMAGINAÇÃO SOCIOLÓGICA, BIOGRAFIA, HISTÓRIA, ESTRUTURA.
\end{abstract}

\section{SOCIOLOGICAL IMAGINATION TO STUDY YOUTHS}

\begin{abstract}
In sociology, there is a particular emphasis on the relevance of W. Mills' contribution with his proposal of the sociological imagination as a way to display knowledge in society and to elaborate its transformation alternatives. In the present conversation, the Chilean sociologist Manuel Canales Cerón reflects on the ways in which the dense observation of youth dynamics in diverse historical processes allows such kind of understanding of social matters. In order to achieve it, Canales connects his own biography as a sociology student, as an educator inside working-class neighborhoods during dictatorship, and as a social scientist today, joining his life story, historical context and structural conditions throughout his reflection; all these three dimensions are simultaneously the three dimensions he applies in his job in order to analyze youthrelated matters critically, and the three dimensions supporting the proposal of sociological imagination.
\end{abstract}

KEYWORDS: YOUTH-RELATED MATTERS, SOCIOLOGICAL IMAGINATION, BIOGRAPHY, HISTORY, STRUCTURE. 


\section{INTRODUCCIÓN}

La presente conversación surge motivada por los aportes que Manuel Canales y su equipo han venido realizando en Chile, como conjunto de claves interpretativas que permiten comprender la crisis social por la que estamos atravesando. Esta ha implicado poner en cuestión el modelo de desarrollo económico que impuso la dictadura militar a fines de los setenta y que hasta ahora sigue vigente; los modos de hacer política y de inhibir la participación de las y los diversos actores sociales en la toma de decisiones sobre aquellos asuntos que inciden directamente en su cotidianidad; y la necesidad de reelaborar la Constitución que rige desde tiempos dictatoriales y que otorga el marco jurídico y legal a los procesos que permiten la desigualdad y el abuso sistemático contra la población.

En medio de este panorama han surgido un conjunto de voces desde las ciencias sociales que buscan aportar a la comprensión de este momento de nuestra historia como país. En específico, desde la sociología, Manuel nos aporta con elementos reflexivos que ubican a las y los jóvenes como actores que condensan en la revuelta social sus descontentos y su esperanza, y también en su análisis estructural e institucional nos muestra cómo expresan las transformaciones de esta sociedad chilena y los cimientos de la desigualdad.

Con Manuel nos conocemos desde tiempos de dictadura, primero en las organizaciones juveniles de la zona sur de Santiago y luego cuando ingresé a estudiar Sociología a la Universidad de Chile el año 1993, él fue mi profesor en varias asignaturas. Además de su aporte en la presente coyuntura, como equipo de la Revista hemos considerado sus contribuciones a los estudios de lo juvenil, desde aquella época dictatorial, y la experiencia que compartimos entre el 2013 y el 2017 en el Proyecto Anillo JUVENTUDES.

Esta entrevista la realizamos en contexto de pandemia, por vía virtual, en un cruce biográfico de estos escenarios compartidos y que son útiles como hilos que nos permitieron tejer la trama de esta reflexión, con énfasis en los modos de hacer investigación social sobre lo juvenil y de qué manera las dinámicas juveniles condensan los procesos estructurales de cada sociedad. Condensa así, en esta conversación, un modo de plasmar la imaginación sociológica en su concreción dentro del oficio que Manuel viene desplegando desde hace más de cuatro décadas. 


\section{JUVENTUD CHILENA: RAZONES Y SUBVERSIONES}

Klaudio DuARTE QuAPPER (KDQ): Hola, Manolo, gracias por aceptar esta conversación. Estaba recordando mientras preparaba el guion, que el libro Juventud Chilena: Razones y Subversiones, que editaste junto a Irene Agurto y Gonzalo de la Maza en 1985 - época de dictadura militar-, lo recibí en un Taller de Educación Popular con jóvenes que se realizó en la Vicaría de la Zona Sur de Santiago. Ahora lo reviso y me pregunto: ¿cómo llegas a vincularte a procesos juveniles y a hacer sociología desde procesos de politización juvenil en sectores populares?

Manuel Canales Cerón (MCC): Cuando entré a estudiar Sociología ya viví una primera sensibilización a la cuestión generacional, a la cuestión de los que veníamos entrando, que no veníamos de la UP (Unidad Popular), porque yo era un niño en la Unidad Popular. Me integro a la Universidad de Chile el año 77 y llega prácticamente una generación muy diezmada, una generación muy chica, muy pequeñita, estaban cerradas las escuelas de Sociología en ese tiempo - la Universidad Católica la tuvo cerrada hasta muy tardíamente-, no había nada en realidad, ni comunidades sociológicas, ni estudiantes, todos con historias muy raras. Y participé de la gestación, de la aparición del primer movimiento estudiantil, que fue un movimiento también en un sentido muy lúcido - como todos los movimientos-, porque como jóvenes observan lo que están viviendo con unos ojos completamente nuevos. De hecho, se nos llamó «adánicos» porque insistíamos en que no se podía observar lo que estaba ocurriendo el año 78-79 con los ojos de la UP, ni con los ojos del Chile de los años 50-60, que ese Chile ya no estaba y que incluso, aunque nosotros éramos hijos directos de esa sociedad, estábamos llamados a «recibirnos» de esa sociedad, por ello teníamos que hacerlo con nuevas claves —en ese sentido lo de «adanes»—.

Bueno, fui expulsado el segundo año de la carrera y me voy a la Población San Gregorio y ahí trabajé con todo el equipo de $\mathrm{FOLICO}^{3}$. El Cucho Valdés, amigo hasta ahora, me llevó para allá y participé de un trabajo precioso en la San Gregorio, en la Población Malaquías Concha, toda la zona sur. Ahí se me aparece tu pregunta: ¿por qué ahí? Porque ahí estaba pasando el corazón de la sociedad también, fue el único momento donde el corazón de la sociedad pasó por la

${ }^{3}$ FOLICO fue una Organización No Gubernamental, creada en el año 1975 como Instituto de Formación de Líderes Cristianos Obreros en la Población San Gregorio, comuna La Granja, en la zona sur de Santiago. 
población, es decir, el actor de contestación a la dictadura donde las contradicciones del régimen social y político, la estructura social haciendo crisis, la crisis económica, además, donde tomó forma fue en la población. Y en la población son los jóvenes y yo estaba ahí, por un asunto político si se quiere, porque coincidía que yo era parte de la protesta y de la sociología militante.

KDQ: Hacer sociología en medio de las protestas.

MCC: En medio de la protesta, porque la protesta era lo que había que estar observando, porque era el modo en que se expresó la sociedad chilena. Era precisamente la muestra de la crisis de hegemonía que se presentó desde entonces, la discordia que dura hasta el 88 . Bueno, y esa realidad tiene mucho de octubre (2019), por ejemplo, hay muchos componentes de octubre que son homólogos en componentes de las protestas de los 80 , no es lo mismo, pero estoy diciendo que hay componentes de una sociedad desconocida que se mostró. Entonces, digo, ¿por qué estaba ahí? Porque en los jóvenes y las jóvenes de la San Gregorio estaba la cuestión sociológica fundamental de Chile en ese momento, o una de las cuestiones. Ahí se estaba jugando el proceso y se estaba jugando la contradicción de la estructura y, es más, se estaba jugando el gobierno, ¡qué más!

\section{LO JUVENIL. INCOHERENCIA SOCIETAL Y PROMESAS INCUMPLIDAS}

KDQ: Siguiendo en esta idea de la emergencia de lo juvenil en la sociedad chilena, ¿cuáles son los asuntos que, desde ese momento hasta ahora, te parecen más relevantes para acercarse a la observación de lo juvenil?

MCC: Creo que lo que he visto en los jóvenes, en los diferentes momentos, podría organizarse sobre la pregunta, por la posibilidad de desarrollar proyectos biográficos coherentes. Porque todos los jóvenes y las jóvenes que yo he escuchado son jóvenes que ya vienen con el mandato moderno del «sálvate a ti mismo», son todos hijos de la sociedad neoliberal, que concurre con la modernidad en general, y este modo exacerbado y hostil, con la idea de la individualidad del año 78, 80. Cuando entro, ya está plenamente desplegada en toda América Latina, por lo demás, estamos en una época de modernización en el sentido primario, básico, por último porque las reglas del juego te van a obligar: «Tú tienes que estudiar, seguir cuarto medio — por lo menos en ese 
tiempo_-, o llegar e intentar estudiar algo más si puedes».

Bueno, pero ¿qué es lo que se me aparecía ahí en ese momento? O sea, hay un asunto claro, con el reconocimiento y la negación permanente, siempre está, de la identidad que se te afirma o se te niega. Pero, sociológicamente del modo más estructural, a mí lo que me ha parecido siempre cómo un joven trae la pregunta o puede preguntarle a la sociedad lo que ese joven está diciendo o está contando: si acaso la sociedad está logrando la prueba de la coherencia, de que ese sujeto pueda decir un relato coherente de lo que va a hacer en su vida y si eso es sostenible. Porque no es tan fácil, de hecho, lo obvio que uno cree es que debe ser así, pregunto a veces medio retóricamente en los foros, porque si mañana vamos a un cuarto medio y un joven me pregunta « ¿y yo qué hago ahora al salir de cuarto medio?», de cualquier colegio estamos hablando, no del ocho por ciento de los colegios particulares, de todos los demás. ¿Qué les dices tú a un joven de cuarto medio? Un silencio total y los tenemos a todos obligados ahí, para pasar por una escena donde cualquiera para el dedo y te preguntan «¿para dónde voy? ¿Qué me recomienda usted?». «No quiero decirte nada, cabro». Porque ya no se animan al «metete ahí, metete acá», porque es complicado.

Y ahí viene la siguiente pregunta, que es algo así como «es importante volver a restituir el empleo, vamos a restituir el empleo», y sale la señora «oiga, párela con la lesera del empleo, también el asunto de los sueldos dignos, si empleo ha habido y va a haber siempre, si es que pagan miserias...». Bueno, lo mismo acá, es pasar la prueba por la propuesta de caminos transitables con coherencia, cualquiera sea. El fundo de alguna manera lo lograba y refundía la cuestión, la modernidad también lo logró de alguna manera como proyectos colectivos donde cabían proyectos individuales, entonces la propia épica, la propia energía colectiva movilizada, agrupaba los proyectos individuales. Así fue en lo personal, de corto alcance, porque le daban una proyección transgeneracional de largo alcance, era la idea de que estaban construyendo una sociedad donde sus hijos, sus nietos y todos iban a ir viviendo ese proceso de dignificación, de progreso, de lo que se quiera. Entonces eso te da un relato coherente también, a través de la política, el otro a través de la religión y este lo hizo en algún momento a través del credo neoliberal. Pero ese credo dejó de creerse, o sea, hemos creído en dios, en la política y en el «sálvate solo», y dejamos de creer en los tres, somos un pueblo ateo ahora. Por eso dejan «la pelota», porque no creen en nada, no creen ni en dios, ni en la política ni en el neoliberalismo.

KDQ: Es una promesa de la sociedad a las y los jóvenes. ¿Qué rol juega esa promesa para comprender la actual revuelta social en Chile? 
MCC: La promesa cumple la función de conformidad, porque lo que un joven trae como pregunta es: ¿me conformo o no me conformo? Es el momento de la conformación, es el momento de la salida de cuarto medio o la salida después cuando no tienes trabajo y «¿qué hago aquí?». Entonces, «yo soy esto, ¿me quedo en esto, me resigno o no? ¿Era esto o no era esto?». Es el momento en que el ideal del yo es el desafío y estas sociedades funcionan a la fuerza, sobre componentes que, a los jóvenes, a las jóvenes populares los sitúan en encuadres de alta incongruencia que se viven con mucho dolor. No es que tampoco los jóvenes, las jóvenes que no son populares no tengan dolores vinculados a las estructuras sociales, que también Freud y todos esos lo estudiaron y es tal cual, se la pasan pésimo igual, pero el modo popular es por la incongruencia de un sistema que sigue anclado a un modo estamental y de asignación de oportunidades, básicamente trabajo simple y que ya no puede ser aceptado por los jóvenes hace rato. Entonces ahí estamos, es la conformidad juvenil, es el momento de la conformación del sujeto y repito, se logró tres veces y el neoliberalismo logró sujetar el ánimo cuando es joven, porque es el momento cuando hay que hacerlo, con los caminos de los estudios superiores del 2005 (2006) para acá y antes lo sujetó desde el 78, desde el 90 al 2005 lo sujetó con el neoconformismo vinculado a la superación de la pobreza. Y antes no fue tan conforme, de hecho, durante la década de los 80 , el año 83 fue protesta y luego volvemos a la conformidad popular, digámoslo así, de los años 40, 50, 60, 70, y luego volvemos a la conformidad inquilina.

Pero la conformidad neoliberal es algo que hay que estudiar, y que se lograba y no se lograba. Por ejemplo, el año 79/80, yo estudiaba la cuestión del disciplinamiento y de la constitución de un sujeto individuado que ya no iba a enlazarse y, por lo tanto, la desaparición de la acción colectiva, la despolitización, todo eso que era parte del régimen. En los 80 , lo que observo es la crisis de ese proyecto, también que no logra desplegarse plenamente y encuentra su resistencia, y la protesta popular y el joven popular. Ahí lo que encuentro es un joven partido en múltiples identidades porque ya no existía la identidad, nunca había habido, porque además son la primera generación en forma de ese segmento sociológico que llamamos «la juventud poblacional urbana». Toda esa multitud es el futuro de Chile y para el futuro de Chile en el momento de la población estaba allá, no había nada casi para los cabros, entonces hubo que entender su rabia, sus protestas, su partición, sus desvíos, sus olvidos, sus activos, neopreno, el delito, el intento de la austeridad extrema como salvación metódica, del bueno, del pentecostal y cada quien tratando de encontrar una coherencia o vivir esa incoherencia, ese vacío, y la protesta donde convergían todos y se 
encontraban todos, y hacían ahí la expresión y la catarsis de identidad.

\section{EL OFICIO SOCIOLÓGICO Y LO JUVENIL}

KDQ: Manuel, estas formas de observación de lo juvenil, vinculado a su condición estructural, a los procesos históricos, articulado con lo biográfico, plantea desafíos a los modos de hacer sociología. ¿Por qué las dinámicas juveniles en sociedad serían útiles en esa dirección?

MCC: Para el conjunto de personas que puedan interesarse en asuntos juveniles o de lo juvenil o de las generaciones, que al final es el estudio de las generaciones, del paso del tiempo, y en ese sentido lo juvenil es siempre una modulación de la transición histórica, por así decirlo. Estoy viendo siempre a los jóvenes de un momento y de una posición en la estructura social. No llego a mirar a los jóvenes propiamente como tales o porque como tales me interesen de modo absoluto. Otra cosa es lo personal, y en alguna fase de la vida en que hay múltiples conexiones, digamos propias, también de tu propia transicionalidad biográfica y de la transicionalidad histórica que hay acompañándote, o de la que tú fuiste parte.

El joven capta el ritmo de los tiempos, entonces por eso ahí miraba la exclusión, la resistencia, el discurso del renegado me acuerdo: «yo ya no creo na', ni una cosa, ya no me preguntís de futuro». ¿Por qué ya no cree en nada? El renegado, ¡claro! Porque ya había un segmento que quería cortar con la conformidad y ese es el que estaba bordeando el delito, era todo un discurso para plantear «porque nos robaron, si todos los caminos están bloqueados, y si los de arriba roban lo que quieren y si los curas roban y si todos roban, y a ver: ¿quién es el juez?». Ese era el discurso del renegado extraordinario y el discurso del discriminado, del que ya decía: «yo quiero estudiar, pero ahí...» — se le perdía la voz- «y tengo problemas económicos y pucha no voy a poder». ¡No vas a poder! Año 89. (Pero) el año 2005 le dicen «tú puedes» y se los llevan a todos con esa ilusión, porque es lo único que necesitaban escuchar, y esa era una palabra a la vena del deseo y a la impotencia popular de siempre: «dicen que quiso querer, pero no pudo poder». Y todo el tema después de los frutos vanos y cuando «más se acerca es cuando se aleja más», como el pacto con el diablo o el entierro. La cosa era para los otros de nuevo.

KDQ: En este contexto de cambio social, ¿se ha transformado tu forma de 
acercamiento a lo juvenil?

MCC: El año 2019-2020 cambió el objeto, cambió también el sujeto, cambió todo. Entonces hoy lo tengo más claro, pero creo poder encontrar esa misma pista, que es que me acerco a la cuestión juvenil siempre en contexto, siempre en una historia de una sociedad y su estructura, donde lo juvenil se me aparece, porque porta, lleva y recibe las contradicciones y distorsiones de esa sociedad, de esa estructura en esa historicidad. Siempre estoy viendo en lo juvenil la clase social, la historia, la historia para delante, la historia presente como lo que se está jugando y toda la historia de formación de esa estructura, también la historia de la formación de su padre, de su abuelo, de su tatarabuelo. Todo eso va junto, porque es asunto de la sociedad que va en esa transgeneracionalidad y va en una continuidad, y va en esa historicidad de la estructura. A los jóvenes y las jóvenes las escucho siempre desde esa clave, no la puedes escuchar, sino digo en relación con esa totalidad social y su proceso, y ahí lo juvenil se me ha revelado una y otra vez como un gran analizador, en parte porque en sí mismo lo es siempre.

KDQ: Cambios sociales con continuidades en los modos de analizar lo social. ¿Por qué lo juvenil sigue siendo un buen analizador de esos cambios y continuidades?

MCC: Porque es del tipo de preguntas que yo creo que los investigadores podemos hacernos sobre las sociedades, que la revelen, que la muestren, digo que a lo mejor lo juvenil en general siempre es un analizador de calidad porque en sociedades como las nuestras, tan historizadas, tan en tránsito continuo, la marca generacional es un dato de la causa, tanto más que la de género, poco visibilizada.

Pero algunos que podrían, y la Revista Última Década va por ahí, pero ¿por qué creo que es un buen analizador? Porque trae la primera seña de lo que la sociedad está viviendo como la zona ignota, como donde la sociedad está en su historicidad misma, donde la sociedad está ocurriendo como acontecimiento, donde no se conoce, se está empezando a olfatear, porque empiezan a salir olores, digámoslo así, de los buenos y de los otros. Todo esto porque todavía no podemos ni verlo ni oírlo, porque el olfato, entiendo, es previo, por eso decimos «que tiene buen olfato», sabe por dónde la sociedad empieza a evaporar sus preguntas, sus tensiones, y lo juvenil es siempre una buena ventana, utilizando la expresión que ocupa Martín Hopenhayn, que estudia el tema de la violencia como una ventana para ver la relación entre lo juvenil y la política. 


\section{LO JUVENIL, ¿UNA METÁFORA DE LO SOCIAL?}

KDQ: Hay quienes plantean lo juvenil como metáfora de la sociedad, ¿qué dices tú sobre ello?

MCC: No usaría primeramente la noción de metáfora, no porque esté inadecuada, sino porque es también una metonimia. $Y$ en ambos sentidos está aludiendo a un asunto complicado de que casi todo es una metáfora del todo, que cada parte es una metáfora del todo, porque está mediado por la totalidad. Cuando yo digo que estudio lo juvenil porque ahí veo la sociedad en su momento apareciente, según se le está apareciendo a los primeros que van entrando, entonces tengo el presente - futuro en plenitud - y cómo en estas sociedades todo es presente y futuro y futuridad, digámoslo así, porque son lanzadas en el tiempo, entonces tengo un muy buen punto de vista siempre.

Puede ser una metonimia, simplemente porque lo juvenil venga mediado por la sociedad; lo que está diciéndose ahí puede entenderse de dos modos: de cómo entender una sociedad, pero también puede estar diciéndose que no puedo entender lo juvenil sino como una pregunta, sino como la sociedad. Eso son dos cosas distintas versus decir que puedo estudiar solo lo juvenil, que ya ni siquiera requiere estudiar la sociedad.

Lo juvenil se hace interesante desde esta perspectiva sociologista, o sociohistoricista o sociopolítica, desde la totalidad de su historia, como lugar de las preguntas. Lo juvenil en general vale porque trae la dimensión de lo nuevo y lo nuevo, la renovación, trae siempre una cara de lo no sabido de la sociedad, de la cara que la sociedad no puede ver porque todavía no lo sabía, no lo conocía. $O$ sea, la sociología es un espacio de ir observando casi anticipadamente al sentido común.

Sin embargo, hay una modulación que hace que lo juvenil sea especialmente interesante, este es su carácter en el tiempo como analizador porque trae la pregunta por lo nuevo, pero también trae y ahí es cuando yo me meto más bien cuando trabajaba en el mercado una y otra vez, o en la política — porque estaba estudiando ese público-, pero no, eso es muy colonizable, no lo hago tanto de estudiar esas prácticas culturales, nuevas y todo eso. Más me ha interesado siempre lo juvenil porque es donde se olfatea la contradicción, es decir, la totalidad se muestra en su incoherencia, en su disfuncionalidad. A eso le llamarán anomia después, porque la gente es disfuncional, porque las cosas no funcionan y cuando la sociedad se pone a prueba, en ese cruce pasa la prueba de la 
coherencia y salen cosas como Jorge González ${ }^{4}$, de «oye mira, no cuadran las cosas». Porque todo está construido sobre un imaginario sociológico que borra todas las contradicciones y es muy difícil superar esa dimensión, te dejan ver algún reclamo, pero no lo incoherente del orden. $\mathrm{Y}$ eso el joven puede en un momento dado verlo, lo ha visto en los 80 , lo vio con los pingüinos (2006), lo vio el 2011 y lo vio ahora (2019-2020), y fíjate que todo el conjunto no puede dejar de ver la incoherencia hasta que ya se calma.

\section{LO JUVENIL HOY Y LO QUE ESTÁ POR VENIR}

KDQ: Manolo, si tú tuvieras que sugerir cuáles son las pistas de lo que se requiere seguir observando en las sociedades y en lo juvenil, ¿cuáles son las preguntas que vienen en las nuevas generaciones jóvenes en este tiempo de revuelta y oportunidades de cambio en Chile?

MCC: Bueno, pueden ser múltiples, infinitas posibilidades a esa pregunta. ¿Qué cuestión veo yo? Es precisamente la prueba de consistencia de las sociedades que construimos y gobiernan, es decir, la cuestión juvenil es la cuestión de la conformidad en unas sociedades, la nuestra es estamental, que individualiza de modo casi forzado y mecánico y condena al trabajo simple. Entonces, esa mentalidad sumada a esa estructura del productor social nuestro, lo que pasa es que los jóvenes tienen que entender que, según su origen de clases, es decir, si son del pueblo o son de la elite, van a ir a la fruta, a la construcción o al comercio, $\mathrm{o}$ van a ir a puestos directivos. Así sea pasando por estudios de cualquier tipo, y eso no se soporta, y creo que es interesante lo nuevo, lo nuevo de estos nuevos jóvenes, que yo creo son la primera generación sin yugo en Chile.

En ese sentido, octubre es una pequeña revuelta francesa, en el sentido de que cayó la sumisión, porque ya había caído en las conciencias de estas generaciones de jóvenes que han tenido que pagar con su propio dolor las incoherencias de los caminos a los que los obligan. Que en ese proceso han desarrollado una consistencia a su vez propia de quien ha hecho ese camino, y lo ha hecho con su esfuerzo, se lo ha financiado y lo debe y lo paga en la deuda. Es decir, todo muy real y muy largo, nada de millennials que hablan solo tonterías, esta gente es de una abnegación y de unos proyectos de largo aliento.

\footnotetext{
${ }^{4}$ Del grupo de rock chileno Los Prisioneros.
} 
Es otro el que falla, no ellos, entonces ese es el conjunto, creo que es el colectivo, que no es colectivo tampoco cuando uno se reúne, salvo en octubre, pero que es reunible por esta homogeneidad de incoherencias biográficas que han cursado y tienen que cursar. Es que en el camino por esa formalización, tanto por lo que estudian como por su propia autoedificación (aunque sea sin estudios), son sujetos libres y ya no se sienten menos. Entonces ese doble componente que fue, creo yo, un rasgo de lo popular desde siempre quizás ya no esté más, y eso es lo que tiene a lo mejor complicado también el diálogo político, porque saben que hay un pueblo nuevo que no se siente menos como siempre, que ya no es un problema como, bueno, «vamos a lograr que te sientas igual», «no, si yo me siento igual», o sea, que «tú parece que no lo estás viendo y no obedeceré».

Ese es quizás todo este tema de la cuestión de la violencia, no es la violencia del saqueo, no es la violencia de la ruptura, de la destrucción, eso es violencia, y ha habido en múltiples contextos. Lo que es nuevo es esa cierta legitimación por un segmento importante de aquello, por razones múltiples y bien contenido, nunca con una suerte de euforia violentista, sino que tomando nota de algunos asuntos interesantes que pasaron y que por último el tema no es mío, o sea... pero no confundiéndose tampoco, a eso me refiero que hay esa dimensión libre, que lo hace ser desprejuiciado también respecto al orden y a los que atentan contra ese orden.

Me preocupa sí que la violencia ocupe el centro del cuento, y eso, pero es debilidad del conjunto, eso va a crecer solo si lo otro no crece, pero sí, hay que politizar hasta poetizar la esperanza de octubre y no solo interpretar su rabia.

RECIBIDO: 6 DE ENERO DE 2021

ACEPTADO: 20 DE ENERO DE 2021

\section{BIBLIOGRAFÍA}

Agurto, I., Canales, M. y De la MazA, G. (1985). Juventud Chilena. Razones subversiones. Santiago de Chile: ECO, FOLICO, SEPADE. 